\title{
Konik Diş Anomalisi Bulunan Sekiz Hastanın Selüloid Şeridi Kron ile Tedavisi
}

\section{Treatment of Eight Patients with Conical Dental Anomaly by the Use of Celluloid Stripe Crown}

\section{ÖZ}

Otozomal dominant geçişli bir bozukluk olduğu bilinen konik diş anomalisi, çocuklar, gençler ve yetişkinler için özellikle psikolojik olmak üzere, fonksiyonel ve estetik olarak problem teşkil etmektedir. Konik diş anomalisine sahip dişlerde birçok tedavi alternatifi olmakla beraber sıklıkla kompozit veneer ile tedavileri tercih edilmektedir. Direkt kompozit ile yapılan selüloid veneer kronlar, varolan anormallikleri, estetik yetersizlikleri ve renk değişimlerini düzeltmek üzere tasarlanan kronlardır. Konik diş anomalisi bulunan hastalarda erken teşhis ve tedavi, içinde bulundukları psikolojik durumu düzeltmeye yardımcı olduğu gibi, ileride oluşabilecek ortodontik düzensizlikleri de engellemek için bir önlem teşkil etmektedir.

$\mathrm{Bu}$ olgu serisinde; konik diş anomalisi bulunan sekiz farklı hastanın klinik değerlendirmeleri ve tanısının konulmasının ardından, olguların selüloid kompozit kron ile konservatif tedavileri sunulmaktadır.

Anahtar sözcükler: Konik diş anomalisi, Selüloid kronlar, Tedavi.

\begin{abstract}
Conical dental anomaly, which is known to be an autosomal dominant disorder, is a functional, aesthetic and especially psychological problem among children, adolescents and adults. In teeth with conical dental anomaly, treatment with composite veneers is often preferred, as well as many alternative treatments. Celluloid veneer crowns made with direct composite are the crowns designed to correct existing anomalies, aesthetic deficiencies and color changes. Early diagnosis and treatment in patients with conical dental anomalies are the measures to prevent orthodontic irregularities as well as help to correct the psychological problems.

In this case series; conservative treatment with celluloid composite crown after the clinical evaluation and diagnosis of eight different patients with conical tooth anomaly is presented.
\end{abstract}

Key words: Conical dental anomaly, Celluloid crowns, Treatment.

\section{Didem ODABAȘI}

Ordu Üniversitesi Diş Hekimliği Fakültesi, Pedodonti Anabilim Dalı, Ordu, Türkiye

Geliş tarihi / Received: 05.12.2017 Kabul tarihi / Accepted: 04.01.2018 DOI: $\operatorname{xxxxxxxxxxx}$
İletişim Adresi/Corresponding Adress:

Didem ODABAŞI

Ordu Üniversitesi Diş Hekimliği Fakültesi, Pedodonti Anabilim Dalı, Ordu, Türkiye Tel/Phone: 05054528336

E-posta/e-mail:dt_odabasi@hotmail.com 


\section{GíRiş}

Konik diş anomalisi, herediter ve otozomal dominant bir bozukluktur. Hipodonti olgusunun başka bir şekli olduğu düşünülen bu anomaliye çoğu kez mikrodonti olgusu da eşlik etmektedir. Etkilenen kişiler için estetik, ortodontik ve periodontal sorunlara yol açan konik dişler diş hekimleri için zor olgulardır. Konik diş anomalisi sıklıkla rastlanılan bir anomali olup, kadınlarda erkeklerden daha sık görülmektedir. Ayrıca süt dişlerinde daimi dişlere oranla daha az sıklıkta görülmektedir. Bu anomali sıklıkla maksiller kalıcı lateral ve üçüncü molar dişler etkilenmektedir. Etkilenen dişler normal boyutlardan daha küçüktür. Genellikle bu dişlerin çivi, kama, silindir, piyano tuşu vb. şekillerdeki konik formlara sahip oldukları izlenir $(1,6)$. Konik formdan sık etkilenen lateral dişler, kama lateral olarak tanımlanmaktadır. Kama lateral, Grahnen tarafından, dişin insizal bölgedeki mezio-distal genişliğinin, servikal genişlikten daha dar olması olarak tanımlanmaktadır (2). Konik lateral dişlerin yaygınlık oranları \% 0,6 - \% 9,9 arasında değişmektedir (3).

Gülmek gençler, yetişkinler ve çocuklar için önemlidir. Özellikle son dönemlerde güzel gülümsemek gibi bir kültür gelişmiştir. Bu kültür çocukları da etkilemektedir. $\mathrm{Bu}$ yüzden dişlerde olabilecek her türlü şekil ve pozisyon bozuklukları önem taşımaktadır. Konik dişler ağızda görüldüğünde, hastanın dişleri diğer dişlerinekıyasla daha küçük ve şekli bozuk olmasından dolayı bir hayal kırıklı̆̆ı olabilir. $\mathrm{Bu}$ anomalilerin hastalarda estetik, fizyolojik ve psikolojik problemlere yol açtığı bildirilmektedir. $\mathrm{Bu}$ anomalilerin erken yaşlarda tanı ve tedavisinin yapılması, hastalarda estetik, fonksiyonel ve psikolojik sorunların önlenmesinden dolayı önemlidir (4). Bu tip dişlerin tedavisinde birçok teknik kullanılabilmektedir. Bunlardan biri kompozit ile direkt restorasyondur.

$\mathrm{Bu}$ olgu bildiriminde; konik diş anomalisi olgusu bulunan sekiz farklı hastadaki konservatif tedavi yaklaşımının sunulması amaçlanmaktadır.

\section{OLGU SUNUMU}

Selçuk Üniversitesi Diş Hekimliği Fakültesi Pedodonti Anabilim Dalı Kliniğine farklı zamanlarda başvuran sekiz çocuk hastanın üst çene ön bölge dişlerinde şekil bozukluğu mevcuttur. Hastaların yapılan klinik ve radyografik muayeneleri sonucunda kesici dişlerdeki şekil bozukluklarının konik diş oldukları tanısı koyulmuştur. Hastaların ailelerinden alınan anamnezde, çocuklarda ve aile bireylerinde herhangi bir genetik ya da sistemik bir hastalık hikayesi bulunmadığı öğrenilmiştir. Çocukların dişlerdeki şekil bozukluklarından psikolojik olarak oldukça etkilendikleri de öğrenilmiştir. Klinik ve radyografik muayene bulguları ve hastaların demografik bilgileri Tablo 1'de özetlenmiştir.

Olgu serisindeki tüm hastaların çiğneme fonksiyonlarını kazandırmak, estetik olarak görünümlerini düzeltmek ve psikolojik olarak daha iyi hissetmelerini sağlamak amacıyla; konik diş anomalisi olan dişler, selüloid kron ile kompozit rezin restorasyonların uygulanmasına karar verilmiştir. Öncelikle, tedavi edilecek dişe uygun boyutta olan şeffaf kronlar seçilmiştir. Daha sonra kronlar konik diş anomalisi olan dişlere uyumlanmıştır (Pediatric

Tablo 1: Klinik ve radyografik muayene bulguları ve hastaların demografik bilgileri.

\begin{tabular}{|c|c|c|c|c|c|c|c|c|}
\hline \multirow{2}{*}{ Olgu no } & \multirow{2}{*}{$\begin{array}{c}\text { Yaş / } \\
\text { Cinsiyet }\end{array}$} & \multirow{2}{*}{$\begin{array}{c}\text { Sistemik } \\
\text { Durum }\end{array}$} & \multirow{2}{*}{$\begin{array}{c}\text { Dental Durum } \\
\text { (intra/ekstra oral } \\
\text { patoloji) }\end{array}$} & \multicolumn{3}{|c|}{ Konik Diş Anomalisi } & \multirow{2}{*}{$\begin{array}{l}\text { Takip } \\
\text { Süresi }\end{array}$} & \multirow[b]{2}{*}{ Şekil } \\
\hline & & & & Diş no & Formu & Tedavi & & \\
\hline Olgu 1 & $11 / \mathrm{K}$ & Normal & Yok & $12-22$ & Kama & \multirow{8}{*}{$\begin{array}{l}\text { Selüloid } \\
\text { kron }\end{array}$} & $5 \mathrm{yil}$ & 1 \\
\hline Olgu 2 & $10 / \mathrm{K}$ & Normal & Yok & $12-22$ & Çivi - Piyano tuşu & & 4 yil & 2 \\
\hline Olgu 3 & $13 / \mathrm{E}$ & Normal & Yok & $12-22$ & Çivi - Piyano tuşu & & 3 yil & 3 \\
\hline Olgu 4 & $11 / \mathrm{K}$ & Normal & Yok & $12-22$ & Kama & & 3 yil & 4 \\
\hline Olgu 5 & $10 / \mathrm{K}$ & Normal & Yok & $12-22$ & Çivi & & 3 yil & 5 \\
\hline Olgu 6 & $13 / \mathrm{K}$ & Normal & Yok & $12-22$ & Çivi - Piyano tuşu & & 3 yil & 6 \\
\hline Olgu 7 & $13 / \mathrm{E}$ & Normal & Ön çapraz kapanış & 12 & Çivi & & 3 yil & 7 \\
\hline Olgu 8 & $5 / \mathrm{K}$ & Normal & Yok & 51 & Kama & & $3 Y_{1} 1$ & 8 \\
\hline
\end{tabular}


Celluloid Crown Forms, Dentorama, Sweden, prod no: 212231). Ardından dişlerin tüm mine yüzeyleri, \% $35^{\prime}$ lik fosforik asitle 60 sn dağlandıktan sonra (iGel- Phosphoric Acid Etching Gel, UK, prod no: 78374), 20 sn suyla yıkanmış, kurutulmuştur. Daha sonra şeffaf kuronlara doldurulup ilgili dişlere uygulanan Grandia anterior kompozit rezin materyal (GC, Japan, lot no: 1706231), vestibül ve palatinalden 40 'ar sn süre ile polimerize edilmiş ve son olarak polisaj diskleri ve kompozit cila frezleri yardımı ile restorasyonları tamamlanmıştır. Her bir hastaya oral hijyen eğitimleri verilmiş ve 6 ayda bir kontrole gelmeleri konusunda uyarılmışlardır. Olgu serisindeki hastalar en az 3 yıldır kontol altındadır. Herhangi bir renk değişimi, hassasiyet, kompozit deformasyonunun söz konusu olmadığı izlenmiştir.

\section{TARTIŞMA}

Otozomal dominant geçiş gösterdiği düşünülen konik diş anomalisi, sendromlarla beraber gözlenebildiği gibi kendi başına da ortaya çıkabilmektedir $(1,7)$. Bu olgu serisinde sunulan her hastanın herhangi bir sendroma bağlı olmaksızın tek başına meydana geldiği bildirilmektedir.

Konik diş anomalisinin lateral dişlerde görülme sıklığ1 yüksek olmakla beraber, en sık üst çene daimi lateral dişlerde gözlenmektedir $(6,7)$. Olgu serimizin altı hastasında da üst çene lateral dişlerin etkilendiği görülmektedir. Nadiren de olsa diğer kesici dişler ve süt dişleri de etkilenmektedir (8). Bu olgu serisinde yer

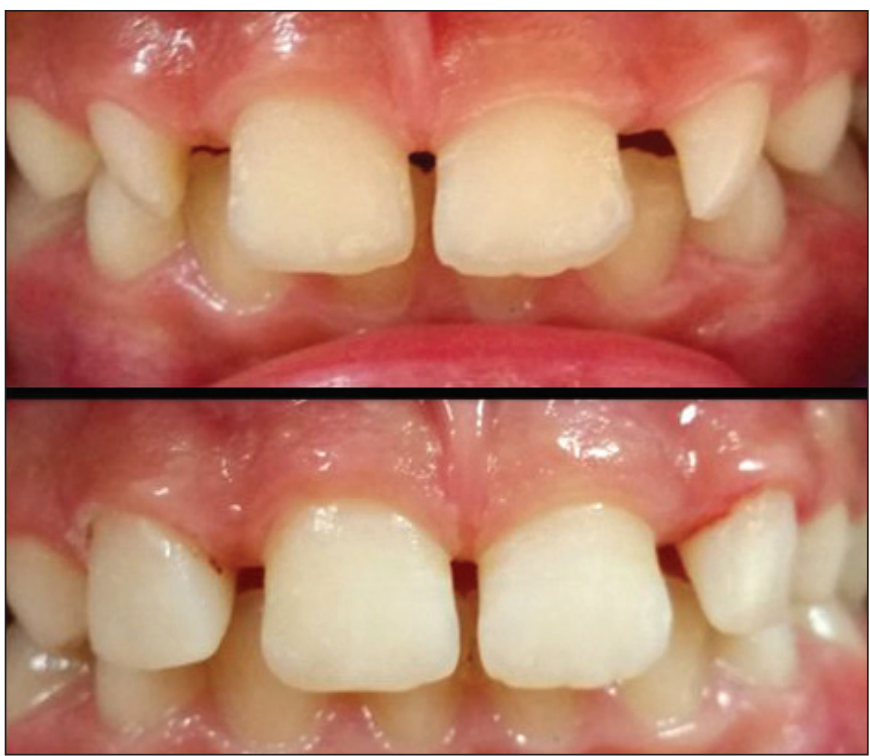

Şeki 1: Olgu 1'e ait 12 ve 22 numaralı dişlerin tedavi öncesi ve sonrası klinik görüntüsü. alan 5 yaşındaki kız hastada süt kesici dişinin etkilendiği görülmüştür.

Konik diş anomalisi olguları yaklaşık \% 65 oranında tek taraflı izlenmesine rağmen (9), olgu serisi raporumuzda, sekiz hastadan sadece iki hastada tek taraflı konik diş anomalisi meydana geldiği izlenmektedir. Konik diş anomalisinin kadınlarda daha sık görüldüğü bildirilmektedir (8). Çocuklar üzerinde yapilan bir çalışmada, konik diş anomalisi olan çocukların \% 58'inin kız olduğu bildirilmiştir. Makalemizde de literatüre benzer şekilde yer alan 8 çocuk hastadan 6'sının kız olduğu görülmüştür.

Konik diş anomalisi olan hastalarda, estetik ve fonksiyonel problemlere klyasla psikolojik problemler daha çok ön plana çıkmaktadır (9). Makalemizde yer alan sekiz hastada da öncelikli problemlerin psikolojik olduğu gözlenmiştir. Bu dişlerdeki konik formun ayrıca sebep olduğu en büyük problemlerden biri de mesiodistal boyutlarının dar olması sebebi ile tedavi edilmediği durumlarda ortodontik problemlere sebep olabilmesidir. $\mathrm{Bu}$ yüzden konik diş anomalisi olan dişlerde erken teşhis ve tedavi önem kazanmaktadır (10). Hastalarımızda yapılan konservatif tedaviye ilave olarak hastalar ortodontik tedavi planlaması için ortodonti kliniğine yönlendirilmiştir.

Konik diș anomalisi olan dișlerin selüloid kronlar ile kompozit veneer tedavisi, hastalarda fonksiyon ve estetik kaybın yeniden kazanılmasının yanında, özellikle psikolojik olarak hastaların memnuniyetini artırmaktadır.

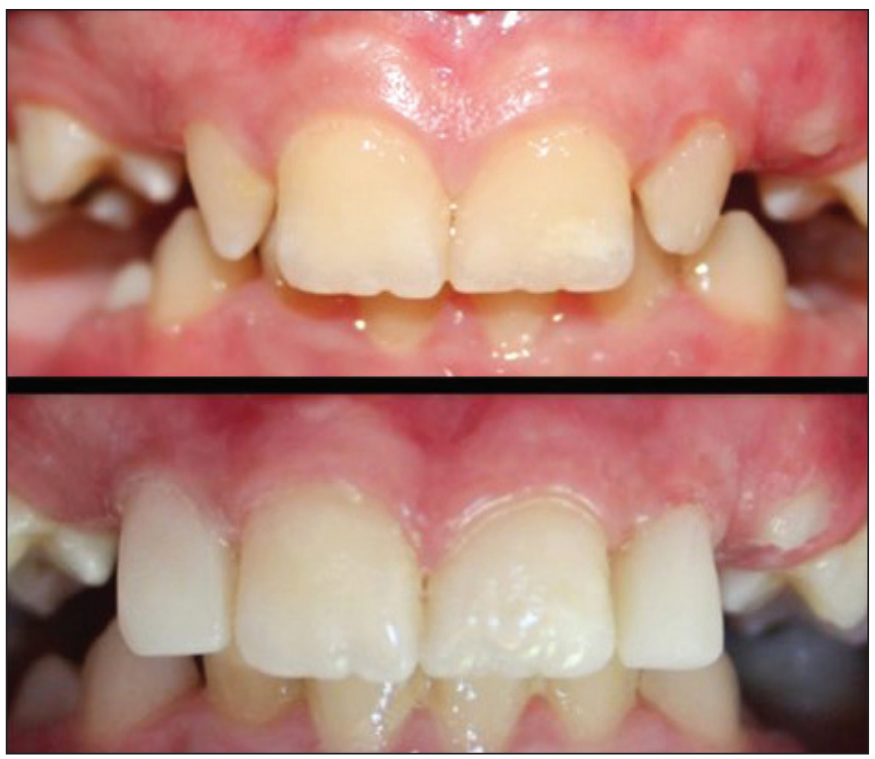

Şekil 2: Olgu 2'ye ait 12 ve 22 numaralı dişlerin tedavi öncesi ve sonrası klinik görüntüsü. 


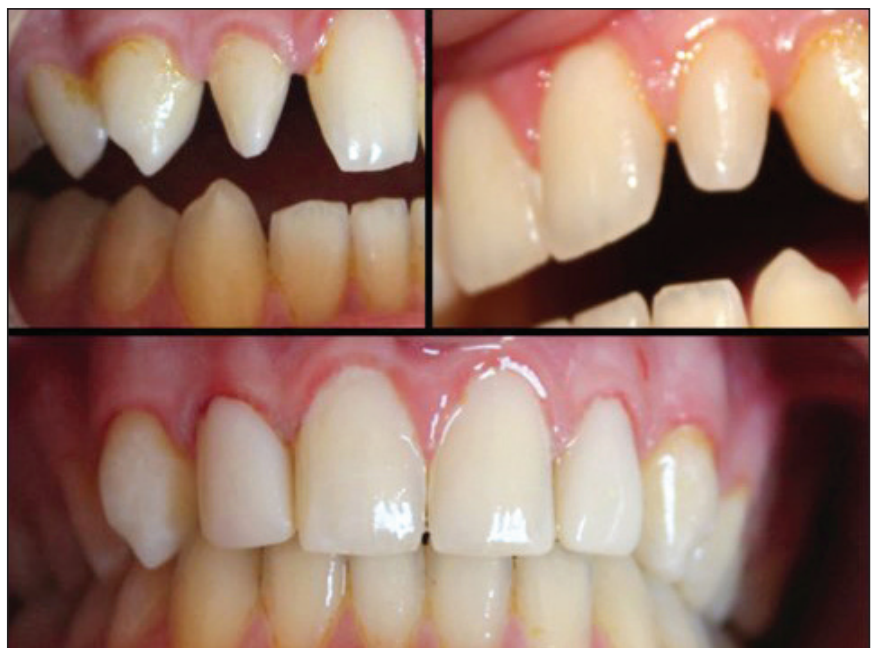

Şekil 3: Olgu 3'e ait 12 ve 22 numaralı dişlerin tedavi öncesi ve sonrası klinik görüntüsü.

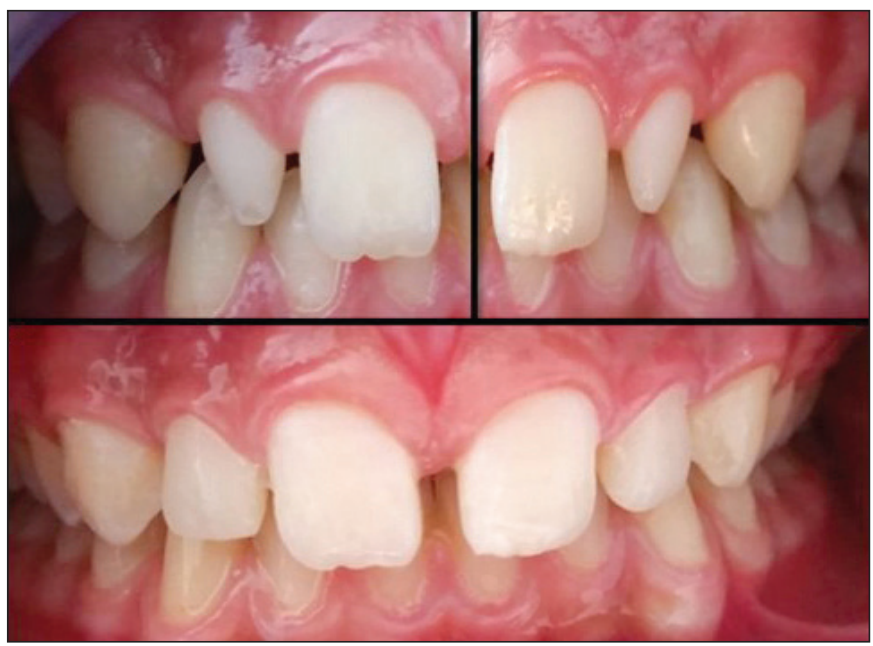

Şekil 4: Olgu 4'e ait 12 ve 22 numaralı dişlerin tedavi öncesi ve sonrası klinik görüntüsü.

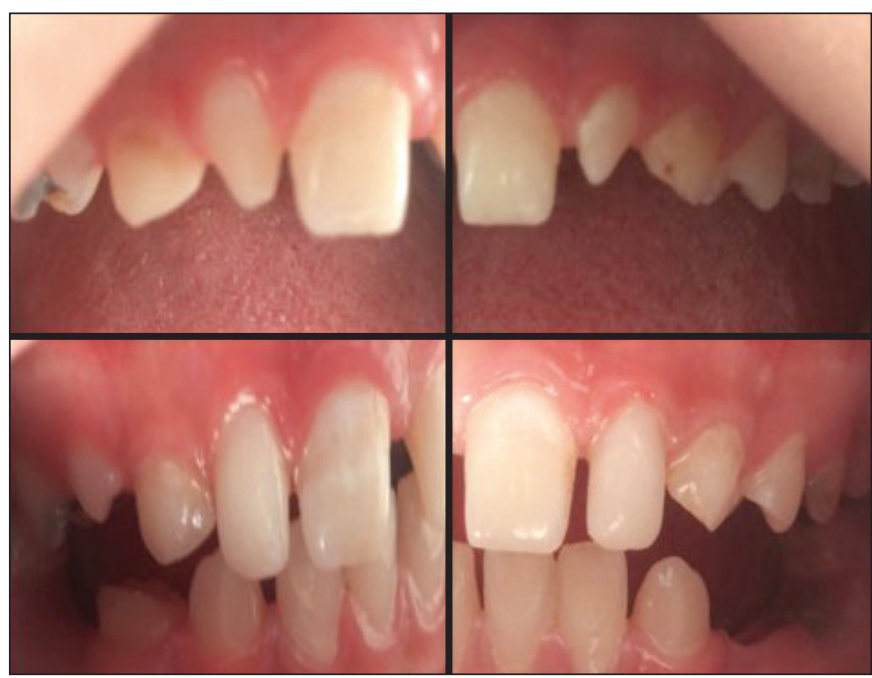

Şekil 5: Olgu 5'e ait 12 ve 22 numaralı dişlerin tedavi öncesi ve sonrası klinik görüntüsü.

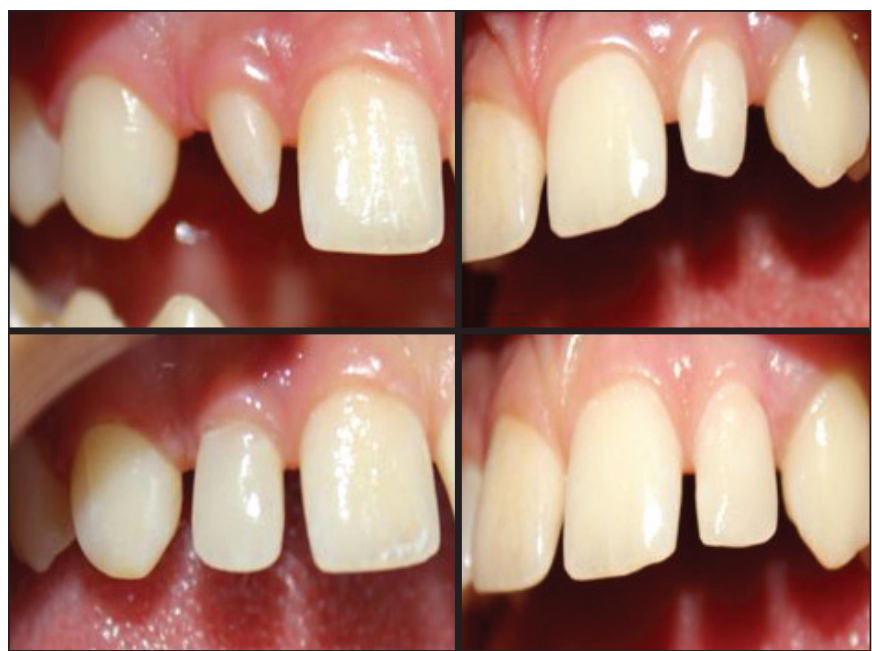

Şekil 6: Olgu 6’ya ait 12 ve 22 numaralı dişlerin tedavi öncesi ve sonrası klinik görüntüsü.

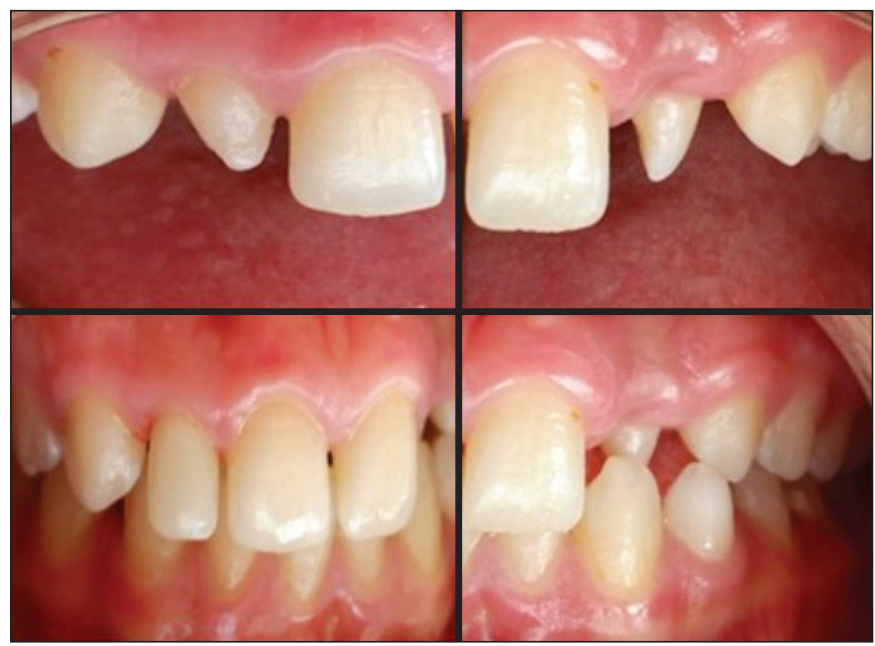

Şekil 7: Olgu 7’ye ait 12 numaralı dişin tedavi öncesi ve sonrası klinik görüntüsü.

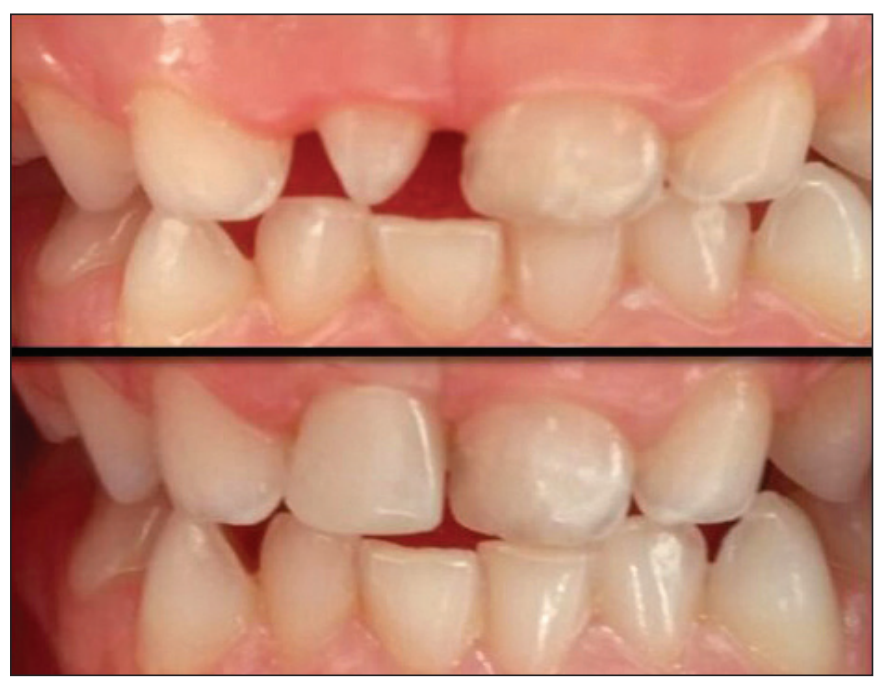

Şekil 8: Olgu 8'e ait 51 numaralı dişin tedavi öncesi ve sonrası bukkalden klinik görüntüsü. 


\section{SONUÇ}

$\mathrm{Bu}$ olgu serisi bildiriminde dişlere uygulanan selüloid kron ile kompozit veneer restorasyonların; hastalarda estetik, fonksiyonel ve özellikle psikolojik açıdan yararlı olduğu bildirilmiştir.

\section{KAYNAKLAR}

1. Kotsomitis N, Freer TJ. Inherited dental anomalies and abnormalities. J Dent Child 1997; 405-8

2. Grahnen H. Hypodontia in the permanent dentition: a clinical and genetical investigation. Odont Rev 1956;7:1100.

3. Thongudomporn U, Freer TJ. Prevalence of dental anomalies in orthodontic patients. Aust Dent J 1998;43:395-8.

4. Millet D, Welbury R. Orthodontics and peadiatric dentistry. Churchill Livingstone, Harcourt Publishers Ltd. 2000;1014.
5. Bacetti T. A controlled study of associated dental anomalies. Angle Orthod 1998;68:267-74.

6. Pinkham JR, Casamassimo PS, Mc Tigue DJ, Fields HW Jr, Nowak A. Pediatric dentistry- infancy through adolescence. W.B. Saunders Co. Philadelphia, Pennsylvania 1999;43-7.

7. Mc Donald RE, Avery DR. Dentistry for the child and adolescent. 7th ed. Mosby, Inc. St Louis, Missouri. 2000;1325.

8. Küçükeşmen Ç, Küçükeşmen HC. "Konik diş anomalisi" bulunan üçfarklı olgunun, kompozit veneer restorasyonlarla estetik ve fonksiyonel tedavisi (olgu bildirimi). A.Ü. Diş Hek. Fak. Derg. 2005;32:215-21.

9. Granat J, Chapelle P. Dental agenesis, hypergenesis and evolution. Actual Odontostomatol 1988;161:31-48.

10. Papadopoulos MA, Chatzoudi M, Kaklamanos EG. Prevalence of tooth transposition. Ameta-analysis. Angle Orthod 2010;80:275-8. 